$1-19-2005$

\title{
Experimental Investigation of Oscillatory Flow Pressure and Pressure Drop Through Complex Geometries
}

\author{
Mounir B. Ibrahim \\ Cleveland State University, m.ibrahim@csuohio.edu \\ Meng Wang \\ Cleveland State University \\ David Gedeon \\ Gedeon Associates
}

Follow this and additional works at: https://engagedscholarship.csuohio.edu/enme_facpub

Part of the Mechanical Engineering Commons

How does access to this work benefit you? Let us know!

Publisher's Statement

Public Domain - NASA Technical Documents - nasa_techdoc_20050182918

\section{Recommended Citation}

Ibrahim, Mounir B.; Wang, Meng; and Gedeon, David, "Experimental Investigation of Oscillatory Flow Pressure and Pressure Drop Through Complex Geometries" (2005). Mechanical Engineering Faculty Publications. 253.

https://engagedscholarship.csuohio.edu/enme_facpub/253

This Conference Proceeding is brought to you for free and open access by the Mechanical Engineering Department at EngagedScholarship@CSU. It has been accepted for inclusion in Mechanical Engineering Faculty Publications by an authorized administrator of EngagedScholarship@CSU. For more information, please contact library.es@csuohio.edu. 


\title{
Experimental Investigation of Oscillatory Flow Pressure and Pressure Drop through Complex Geometries
}

\author{
Mounir B. Ibrahim' and Meng Wang ${ }^{2}$ \\ Mechanical Engineering Department, Cleveland State University, Cleveland, OH, 44115-2425 \\ and \\ David Gedeon ${ }^{3}$ \\ Gedeon Associates, Athens, $\mathrm{OH}, 45701$
}

\begin{abstract}
A series of experiments have been performed to investigate the oscillatory flow pressure and pressure drop through complex geometries. These experiments were conducted at the CSU-SLRE facility which is a horizontally opposed, two-piston, single-acting engine with a split crankshaft driving mechanism. Flow through a rectangular duct, with no insert (obstruction), was studied first. Then four different inserts were examined: Abrupt, Manifold, Diverging Short and Diverging Long. The inserts were mounted in the center of the rectangular duct to represent differeat type of geometries that could be encountered in Stirling machines. The pressure and pressure drop of the ascillating flow was studied for: 1) different inserts, 2) different phase angle between the two pistons of the engine (zero, 90 lead, 180 and $90 \mathrm{lag})$, and 3 ) for different piston frequencies $(5,10,15$ and $20 \mathrm{~Hz})$. It was found that the pressure drop of the oscillatory flow increases with increasing Reynolds number. The pressure drop was shown to be mainly due to the gas inertia for the case of oscillatory flow through a rectangular duct with no insert. On the other hand, for the cases with different inserts into the rectangular duct, the pressure drop has three sources: inertia, friction and local losses. The friction pressure drop is only a small fraction of the total pressure drop. It was also shown that the dimensionless pressure drop decreases with increasing kinetic Reynolds number.
\end{abstract}

\section{Nomenclature}

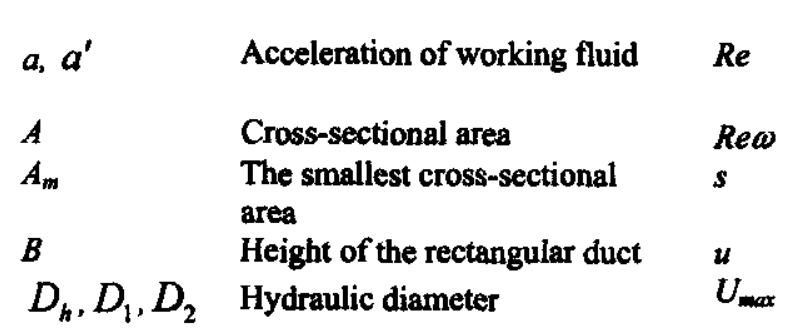

Reynolds number $\frac{u D_{h}}{v}$

Kinetic Reynolds number Stroke of the piston

Area-averaged fluid velocity

Fluid velocity $\frac{2 \pi \omega x_{\max }}{2}$

\footnotetext{
' Professor, Department of Mechanical Engineering, Room 261, Stilwell Hall, Cleveland State University, 1960 East 24 Street, Cleveland, OH and AIAA Associate Fellow.

${ }^{2}$ Research Assistant, Department of Mechanical Engineering, Stilwell Hall, Cleveland State University, 1960 East 24 Street, Cleveland, OH.

${ }^{3}$ Consultant, Gedeon Associates, 16922 South Canaan Road, Athens, OH, 45701 and AIAA Member.
} 


\begin{tabular}{|c|c|c|c|}
\hline & $\begin{array}{l}\text { Pressure drop factor due to skin } \\
\text { friction }\end{array}$ & $V_{p i s}$ & Swept volume of the piston \\
\hline & Thickness of the insert & $w$ & Width of the rectangular duct \\
\hline & Length of the channel & $x_{\max }$ & Displacement of the fluid $\frac{V_{p i s}}{A_{m}}$ \\
\hline${ }_{2}^{\prime}, M_{3}$ & Mass of working fluid & Greek Letters & \\
\hline & Pressure of fluid & $\theta$ & $\begin{array}{l}\text { Angle shown in Figure } 3.24 \text { and } \\
3.25\end{array}$ \\
\hline & Pressure drops & $\rho$ & Density of fluid \\
\hline & Cycle-averaged pressure drop & $\omega$ & Frequency of the piston \\
\hline$P^{*}$ & $\begin{array}{l}\text { Dimensionless cycle-averaged } \\
\text { pressure drop }\end{array}$ & $v$ & Kinetic viscosity of fluid \\
\hline & Radius of the piston & $\begin{array}{l}\xi_{l o c}, \xi_{l o c, e}, \xi_{l o c, c} \\
, \xi_{l o t}, \xi_{s, e}, \xi_{s, c}\end{array}$ & $\begin{array}{l}\text { Coefficient of local fluid } \\
\text { resistance }\end{array}$ \\
\hline
\end{tabular}

\section{INTRODUCTION}

$\mathrm{T}$

HE oscillatory flow pressure drop in the regenerator and heat exchangers plays an important role in the Stirling engine performance. The understanding and prediction of the oscillatory flow pressure and pressure drop, in engine-like components, are crucial in the optimal design of regenerative thermal machines and other reciprocating machines. Currently the modeling of most of the components in these regenerative thermal machines relies on correlations derived from steady-state unidirectional flow assumptions. Therefore, a more detailed analysis of the heat transfer and pressure drop associated with oscillating flow is required for all components of regenerative thermal machines.

Tanaka, Yamashita and Chisaka ${ }^{1}$ described the flow friction and heat transfer characteristics of various types of regenerator materials (wire netting, sponge metal and sintered metal) under oscillating flow conditions. Zhao and Cheng ${ }^{2}$ investigated oscillatory pressure drop characteristics in packed columns (composed of three different sizes of woven screen) subjected to a periodically reversing flow of air. Later, Lee, Kang and Lee ${ }^{3}$ investigated the effects of the regenerator materials on the regenerator effectiveness in an oscillating flow. Ju, Jiang and $\mathrm{Zhou}^{4}$ designed a dynamic experimental apparatus to investigate oscillating flow characteristics in a regenerator.

The Darcy friction factor is related to the pressure drop over a length $L$ by the following equation:

$$
f=\frac{\Delta P D_{h}}{\left(\rho u^{2} / 2\right)^{L}}
$$

where $\Delta P$ is the pressure drop, $u$ is the cross-sectional mean flow velocity and $\mathrm{L}$ is the distance between the two positions where the pressure is estimated.

For steady laminar flow in circular pipes, $f$ is given by:

$$
f=\frac{64}{\operatorname{Re}}
$$

For steady turbulent flow regime, $f$ is estimated by:

$$
f=\frac{0.3164}{\operatorname{Re}^{0.25}}
$$

In a duct with abrupt expansion or contraction in the cross section, local pressure losses occur. The local resistance coefficient is defined as: 


$$
\xi_{b c}=\frac{\Delta P}{\rho u^{2} / 2}
$$

For a uniform velocity distribution over the cross section of the upstream channel, the local resistance coefficient of the expansion can be calculated from the Borda-Carnot formula (Vennard ${ }^{12}, 1961$ ) as follows:

$$
\xi_{l o c, e}=\frac{\Delta P}{\rho u^{2} / 2}=\left(1-\frac{D_{1}}{D_{2}}\right)^{2}
$$

For the contraction, the local resistance coefficient (Fried and Idelchik ${ }^{13}, 1989$ ) is given by:

$$
\xi_{\text {loc }, \mathrm{c}}=\frac{\Delta P}{\rho u^{2} / 2}=0.5\left(1-\frac{D_{1}}{D_{2}}\right)^{3 / 4}
$$

For steady flow passing through ducts or pipes with different geometries, Fried and Idelchi ${ }^{13}$ published "Flow Resistance: A Design Guide for Engineers", in which practical data for the evaluation of internal fluid pressure losses are provided. Su and $\mathrm{Lin}^{5}$ conducted experimental studies for flows in convergent and divergent ducts of rectangular cross section.

On the other hand, for the oscillatory flow condition, Ni and Gouth ${ }^{6}, 1997$ presented a discussion on the dimensionless groups governing oscillatory flow in a baffled tube. Smith and Swift ${ }^{7}$ (2003) performed some experiments on oscillatory flow at the abrupt transition between a two-dimensional channel and essentially infinite space.

Chen and Griffin ${ }^{8}$ (1983) studied the pressure drop correlations for Stirling engine applications. Their study indicated that the regenerator pressure drop has a significant effect on the engine efficiency and power output. And the pressure drop in the regenerator is nearly a linear function of velocity. Also, they found the ratio of friction factor between oscillatory and steady flow only varies with the kinetic Reynolds number.

In this paper we describe some of the research effort that was conducted at Cleveland State University (CSU) with the following objectives: (1) to design and build a data acquisition system for the CSU-SLRE (Stirling Laboratory Research Engine) with the capability to measure the pressure, pressure drop and crank angle with high speed (up to $60 \mathrm{~Hz}$ ), (2) to analyze the pressure and pressure drop signals in a rectangular channel for both no-insert and different inserts (of different geometries), for various Reynolds numbers and for different phase angles between the two pistons (see Figure 1), (3) to study the variation of dimensionless pressure drop as a function of kinetic Reynolds number for different inserts and (4) to compare the local flow resistance loss i.e. "minor" or "end effect" loss, of oscillating flow with steady flow at the same geometry.

\section{EXPERIMENTAL DETAILS}

The experimental facility is shown in Figure 1. The SLRE, as originally designed and fabricated, is a horizontally opposed, two-piston, single-acting engine with a split crankshaft driving mechanism. The test section is a parallelepiped with $17.3 \mathrm{~mm}$ width, $173 \mathrm{~mm}$ height and $300 \mathrm{~mm}$ length (see Figure 2.). In these tests, the working gas (air) passes through the test section mounted between two transition sections, which in turn are connected to the two cylinders (with two pistons) of the engine. The transition sections, connecting the piston head to this test section, have a rectangular cross section (17.3 $\mathrm{mm}$ width and 173 $\mathrm{mm}$ height) on one end and a square section $(52.9 \times 52.9 \mathrm{~mm})$ on the other. This design was made to ensure smooth transition of the flow from piston head to the test section. Thus the maximum volume of the test section is $0.002687 \mathrm{~m}^{3}$ with both of the two pistons at BDC, while the minimum volume is $0.002237 \mathrm{~m}^{3}$ with both of the two pistons at TDC. 


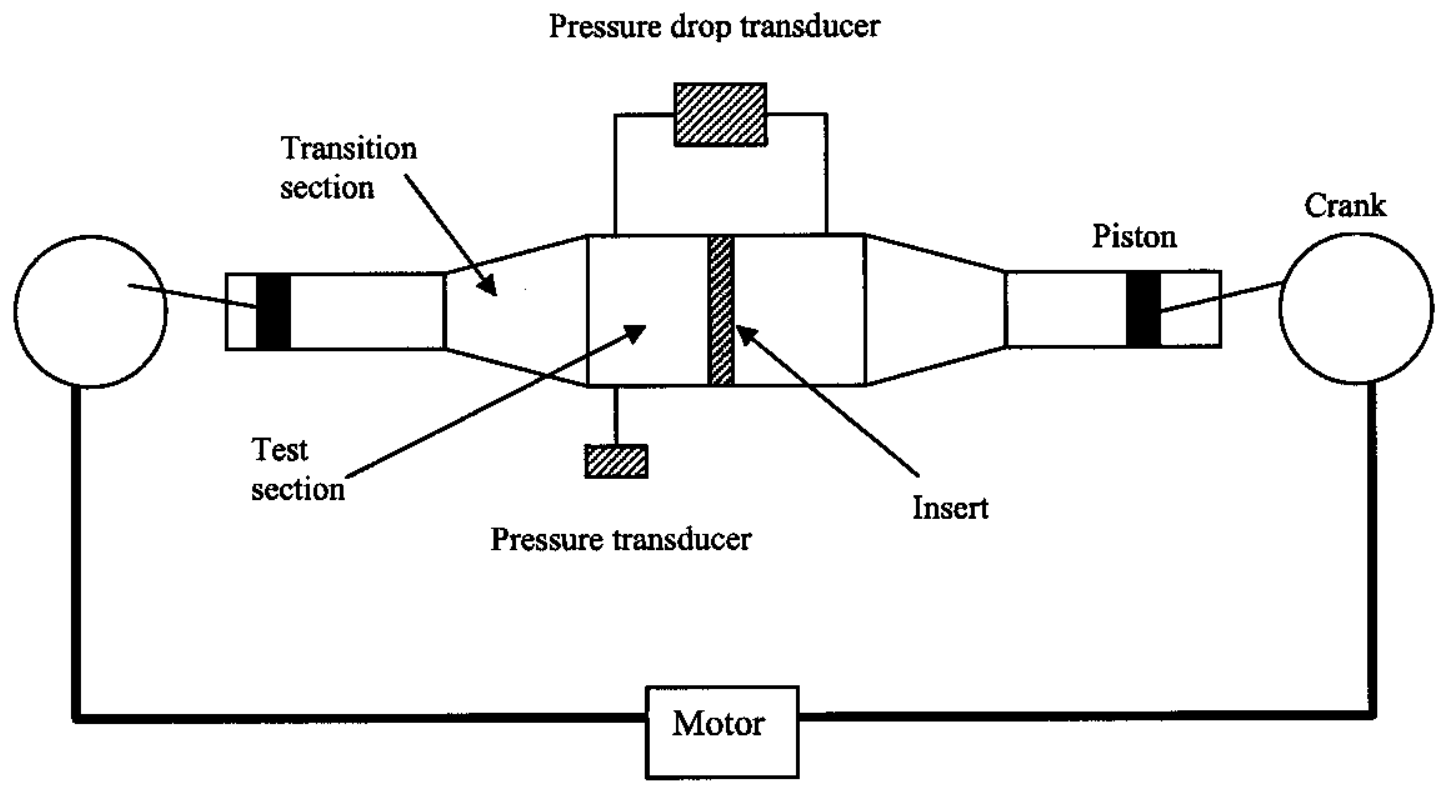

Figure 1. Schematic Diagram of the Experimental Apparatus.

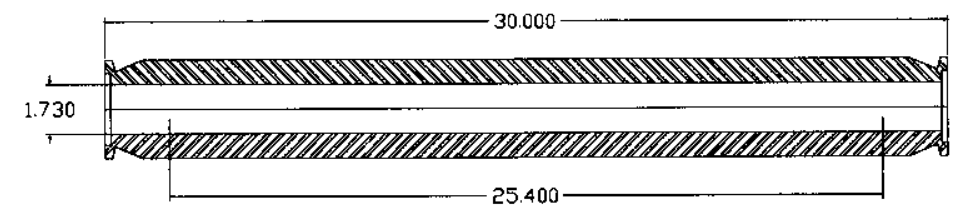

Figure 2. Rectangular Duct (no insert).

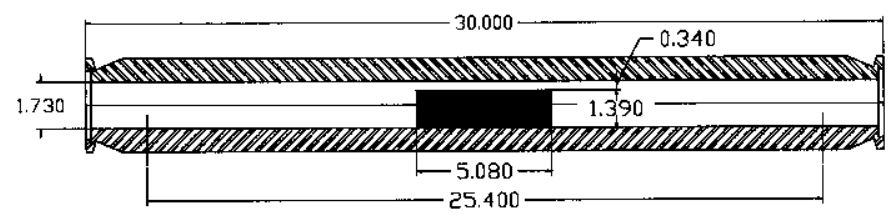

Figure 3. Rectangular Duct with an "Abrupt" insert.

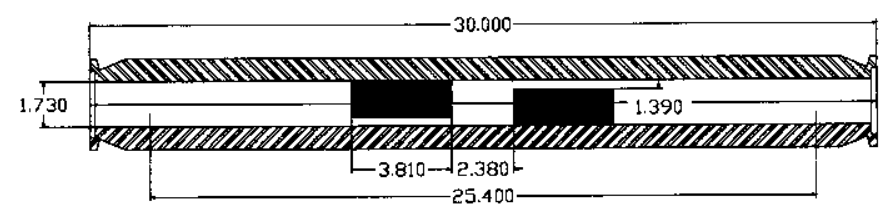

Figure 4. Rectangular Duct with a "Manifold" 


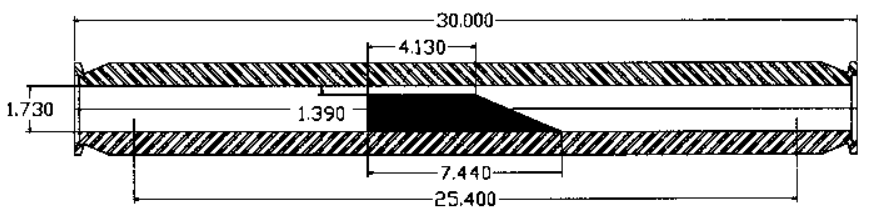

Figure 5. Rectangular Duct with a "Diverging" short

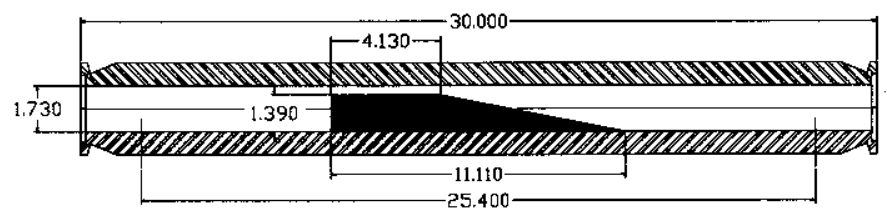

Figure 6. Rectangular Duct with a "Diverging" long insert.

Figure 2 shows the rectangular test section while the different type inserts used in this study are shown in Figures from 3 to 6 . These inserts were mounted in the central part of the rectangular test section. Oscillatory flow pressure and pressure drop through the rectangular duct (with no insert) were studied first. Then four different inserts were used: Abrupt (ABRU) in Figure 3, Manifold (MANI) in Figure 4, Diverging Short (DIVS) in Figure 5 and Diverging Long (DIVL) in Figure 6. Note that insert dimensions are defined in these figures. The pressure and pressure drop of the oscillating flow was studied for: 1) different inserts, 2) different phase angles between the two pistons of the engine (zero, 90 lead, 180 and 90 lag), and 3) for different piston frequencies $(5,10,15$ and $20 \mathrm{~Hz})$. The zero degree phase angle difference between the two pistons means that one piston is at the Top Dead Center (TDC) when the other piston is also at the TDC. The 180 degree means that one piston is at the TDC when the other is at the Bottom Dead Center (BDC). After one piston was chosen as the reference piston, the 90 degree lead or lag, represented the phase of the $2^{\text {nd }}$ piston's motion relative to that of the reference piston.

Different experimental cases were represented with a particular code such as: insert-frequency-phase angle difference, e.g. [ABRU-5-90 lead] indicates an abrupt insert, frequency $=5 \mathrm{~Hz}$ and the phase angle difference $=90$ lead.

\section{RESULTS AND DISCUSSION}

In this section, we present the experimental results of pressure and pressure drop through the rectangular duct with no insert and then with different insert (obstruction) geometries.

\section{A. Pressure data for $\mathbf{1 8 0}$ degree phase angle difference with no inserts}

The 180 degree phase difference cases (when one piston is at TDC, the other will be at BDC) have the lowest pressure change inside the test section, since for this case the two pistons are moving in the same direction with the same speed. The measured pressure versus crank angle data for the no-insert $(\mathrm{N}-5,10$, 15, 20-180) cases are presented in Figure 7. It is shown that the pressure data for different frequencies with no-insert are very similar. Figure 7 shows two peaks in one cycle (rather than one) and they do not have the same magnitude. These two peaks are due to the fact that the piston motions are not perfect sinusoidal functions. When the two pistons move at " 180 phase angle" difference, the total volume of the working gas changes slightly. Also as seen from this figure, the signals are not symmetric about the 180 crank angle. This is due to the fact that the phase angle difference between the two pistons is not exactly 180 degrees. $\mathrm{A}$ small error in the phase angle, such as phase drift from the belts, will cause such an unsymmetrical result. 


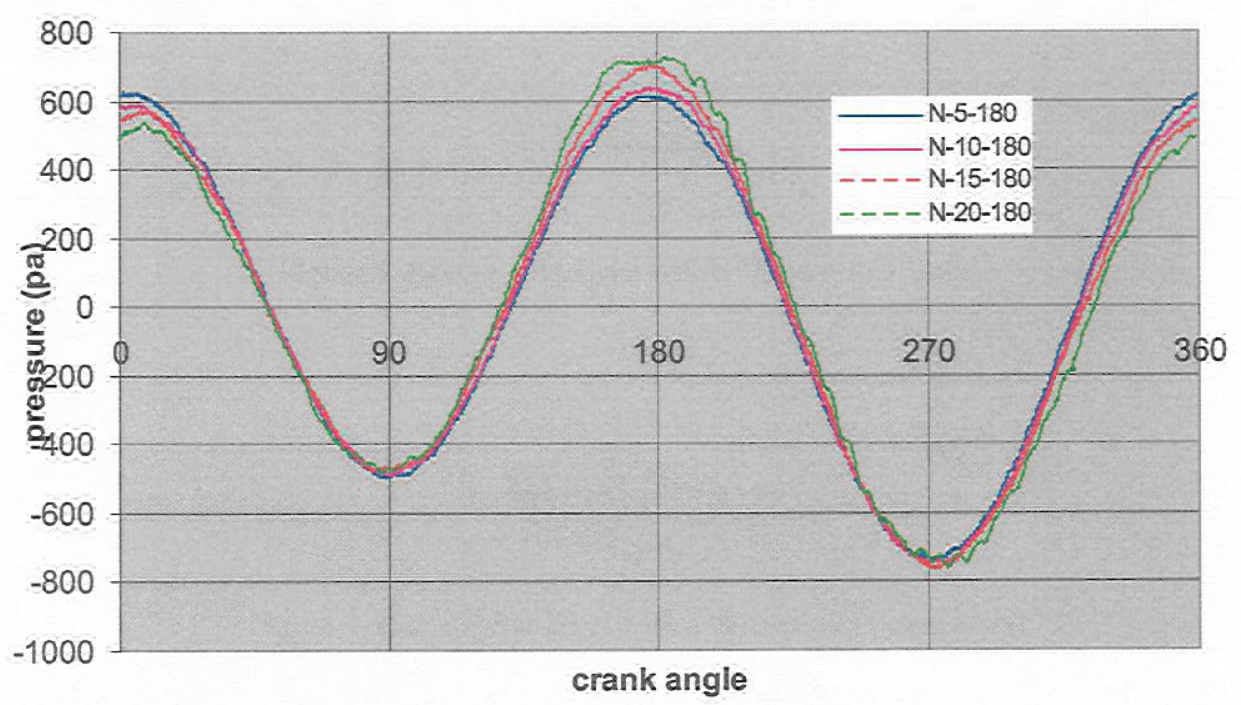

Figure 7. Experimental Pressure Signal of N-5, 10, 15, 20-180 Cases

Using the motions of the two pistons to calculate the pressure inside the test section, Figure 8 shows the results of the pressure variation inside the test section for 180 degree phase angle difference between the two pistons. On the other hand, Figure 9 shows the pressure variation with 182 degree phase angle difference between the two pistons. The two degrees phase angle difference resulted in a change of the negative pressure "peak" from being $600 \mathrm{~Pa}$ to two peaks at 400 and $800 \mathrm{~Pa}$. Further more, there are differences among the four pressure signals (frequency $=5,10,15$ and $20 \mathrm{~Hz}$ ) as shown in Figure 7 . This is because the pressure transducer was not installed exactly in the middle of the test section. As the frequency (flow velocity) goes higher, the pressure difference between the middle of the test section and the location of the pressure sensor will increase. The biggest difference appears at the TDC and BDC, because the maximum inertial pressure drop happens at TDC and BDC.

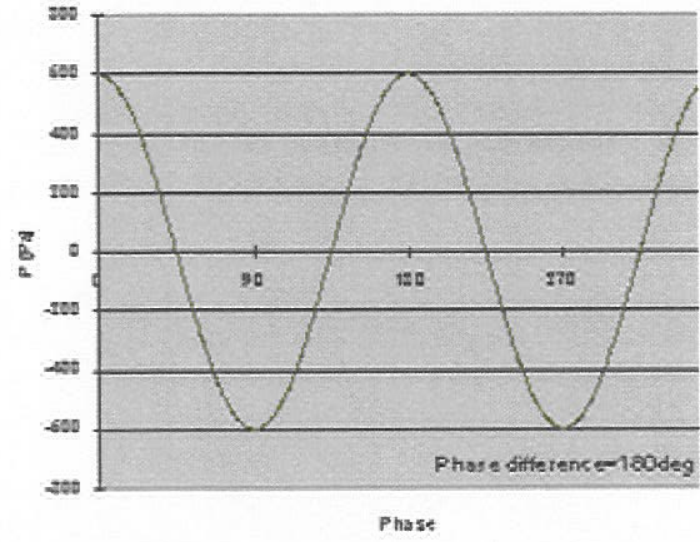

Figure 8. Calculation of Pressure Signal at 180 Degree Phase Angle Difference

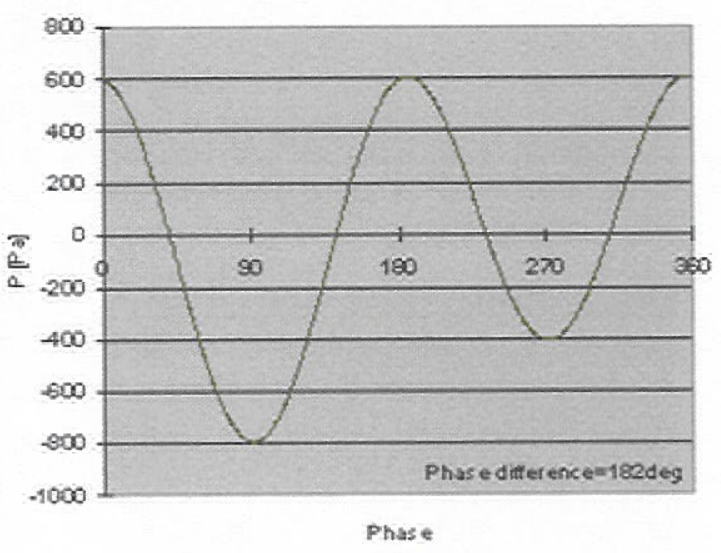

Figure 9. Calculation of Pressure Signal at 182 Degree Phase Angle Difference 


\section{B. Pressure drop of oscillatory flow through rectangular channel (test section without insert)}

Figure 10 shows the pressure drop versus crank angle for the cases of no insert, 180 phase angle difference and frequencies 5,1015 and 20 . For our case we have a channel with $D_{h}$ (hydraulic diameter) $=$ $0.0309 \mathrm{~m}, \mathrm{~L}$ (length in the flow direction) $=0.3 \mathrm{~m}$ and aspect ratio $=10$, or an $\mathrm{L} / \mathrm{D}_{\mathrm{h}}$ value of 9.7 .

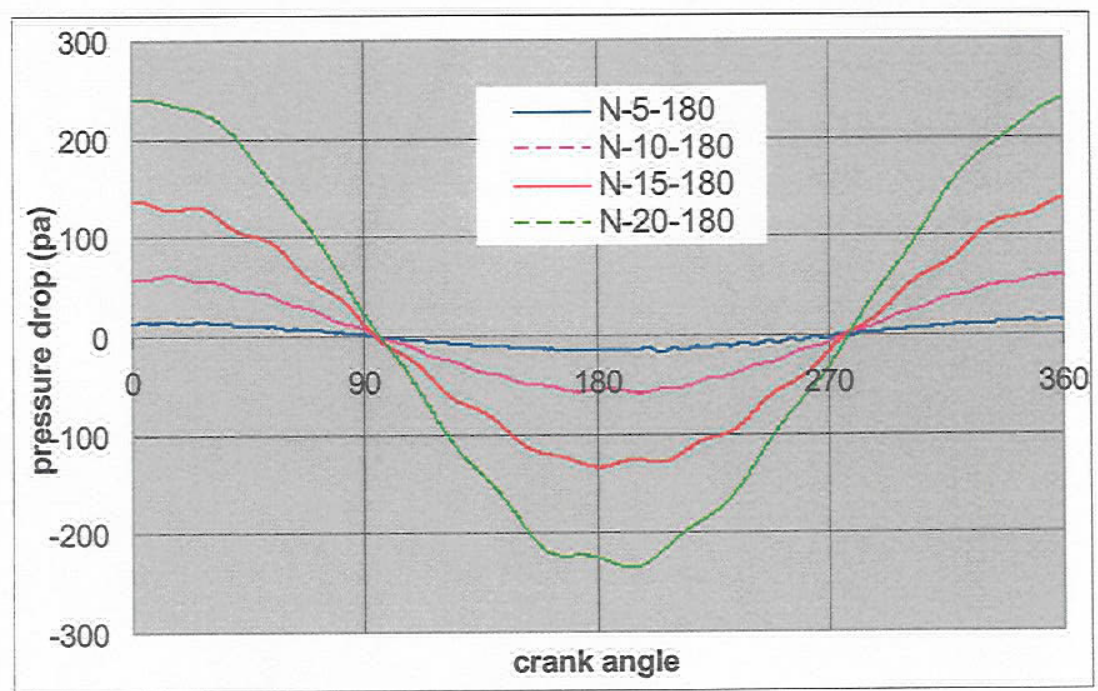

Figure 10. Experimental Pressure Drop Signal of N-5, 10, 15, 20-180 Cases.

For steady flow we used two correlations for friction factor: (1) fully developed flow and (2) developing flow. The correlation used for the steady flow condition, fully developed and with aspect ratio $=10$ is:

$$
f \cdot \operatorname{Re}=21.17
$$

For the developing laminar flow condition, the correlations between the $L /\left(D_{h} \cdot R e\right)$ (from 0.002 to 0.1 ) and $f \cdot R e$ were shown schematically for different aspect ratios in Figure 41 in the book "Laminar Flow Forced Convection in Ducts", by Shah and London ${ }^{14}$. From their results:

$$
f \cdot \operatorname{Re} \approx 65
$$

Table 1 shows the maximum pressure drop obtained experimentally together with friction pressure drop obtained from steady state correlations. In comparing between the oscillatory and steady flow cases we used the quantities obtained at the maximum Reynolds number. Taylor and Aghili ${ }^{9}$ (1984) studied the friction factor correlations between the steady flow and oscillatory flow in tubes. They found the oscillatory flow friction factor was 3 to 4 times larger than the steady flow when L/D equals to 13.7 and Reynolds number is from $10^{3}$ to $10^{5}$. We can see from Table 1 that the maximum experimental pressure drop, at the maximum oscillatory-flow Reynolds number were hundreds of times larger than the unidirectional-flowfriction pressure drops. Therefore, we conclude that the oscillatory-flow pressure drop measured in the rectangular duct used in this study was not a frictional pressure drop.

The velocity and acceleration profiles of each piston can be calculated from its displacement. By assuming that the working gas moves at the same pace as the pistons (for the real situation, there is some lag between the motions of the gas and the pistons), the gas inertial pressure drop can be calculated from the known acceleration by:

$$
\Delta P=\rho \cdot l \cdot a
$$


Table 1 The maximum experimental pressure drop and the calculated steady-flow frictional pressure drop, both corresponding to the maximum oscillatory flow Reynolds number, at different frequencies.

\begin{tabular}{|l|l|l|l|l|}
\hline $\begin{array}{l}\omega \\
(\mathrm{Hz})\end{array}$ & Re,max & $\begin{array}{l}\text { Fully developed flow } \\
\Delta \mathrm{P}(\mathrm{pa})-\text { Steady Flow }\end{array}$ & $\begin{array}{l}\text { Developing flow } \Delta \mathrm{P} \\
(\mathrm{pa}) \text {-Steady Flow }\end{array}$ & $\begin{array}{l}\text { Measured max } \Delta \mathrm{P} \\
\text { (present work) (pa) }\end{array}$ \\
\hline 5 & 3319 & 0.088 & 0.269 & 16.95 \\
\hline 10 & 6637 & 0.175 & & 60.49 \\
\hline 15 & 9956 & 0.263 & & 137.14 \\
\hline 20 & 13275 & 0.350 & & 239.28 \\
\hline
\end{tabular}

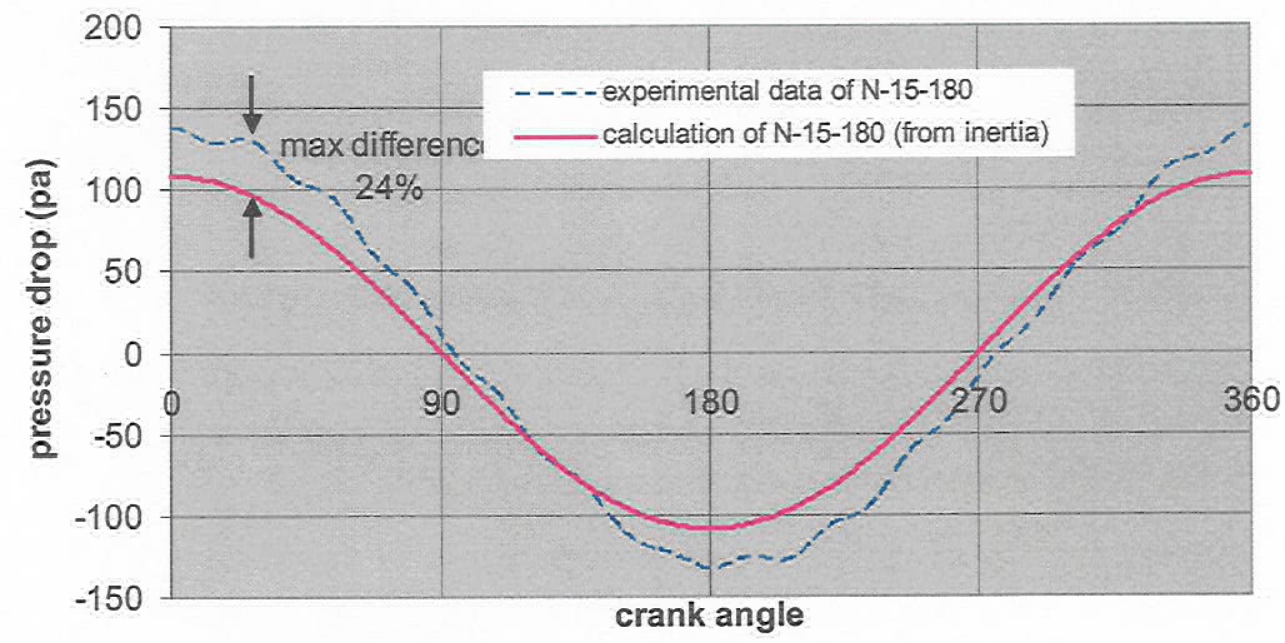

Figure 11. N-15-180 Pressure Drop Comparisons between No-Insert (N-15-180) Experimental Data and the Inertial Pressure-Dron C.alculation Results

Figure 11 compares the pressure drop curve (N-15-180) obtained in these experiments with the one calculated for the inertial pressure drop using equation (9). As can be seen, although there's a difference in the magnitude (maximum difference $24 \%$ ) and a slight difference in the phase, these two curves are similar. The difference in the magnitude is thought to be due to the fact that a fraction of the measured pressure drop is due to skin friction; the mismatch in the phase is, then likely, due to the fact that the maximum value of the frictional pressure drop occurs at 90 and 270 degrees phase angle (at maximum piston velocity) while the maximum value of the inertial pressure drop occurs at 0 and 180 degrees phase angle (at the maximum piston acceleration). The overall good agreement shown in Figure 11 further justifies the conclusion that the pressure drop of oscillating flow in the rectangular duct under investigation, is mostly due to the gas inertia.

\section{Pressure drop of oscillatory flow through rectangular channel with different inserts}

Figures 12 to 15 show the experimental oscillatory pressure drop for the four different inserts inside the rectangular duct. The pressure drops for oscillatory flow through the rectangular duct with no insert were mainly from the inertia as shown before. However the pressure drop for oscillatory flow through the rectangular duct with inserts will be shown to come from three different sources: inertia, local losses (minor or end effects loss) and skin friction (which is thought to be small based on the previous comparison for no insert). 


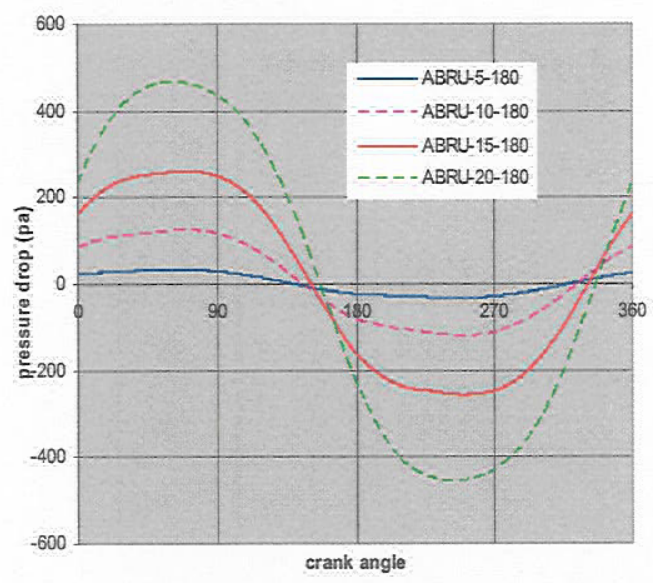

Figure 12. Experimental Pressure Drop Results of Four Abrupt Inserts (ABRU-5, 10, 15, 20 180) Cases.

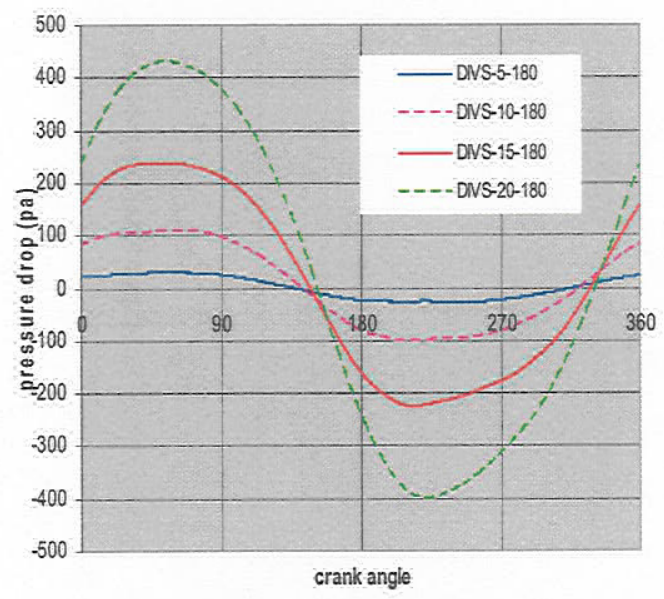

Figure 14. Experimental Pressure Drop Results of Four Short Diverging Inserts (DIVS$5,10,15,20-180$ ) Cases.

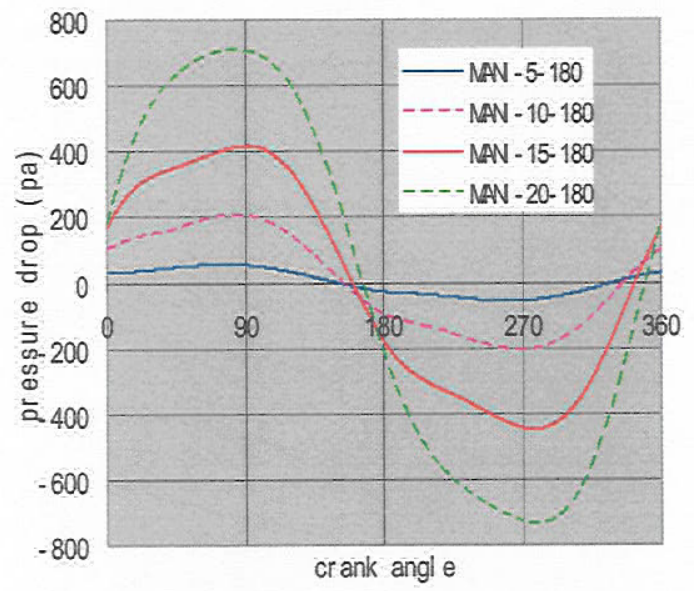

Figure 13. Experimental Pressure Drop Results of Four Manifold Inserts (MANI-5, 10, 15, 20-180) Cases.

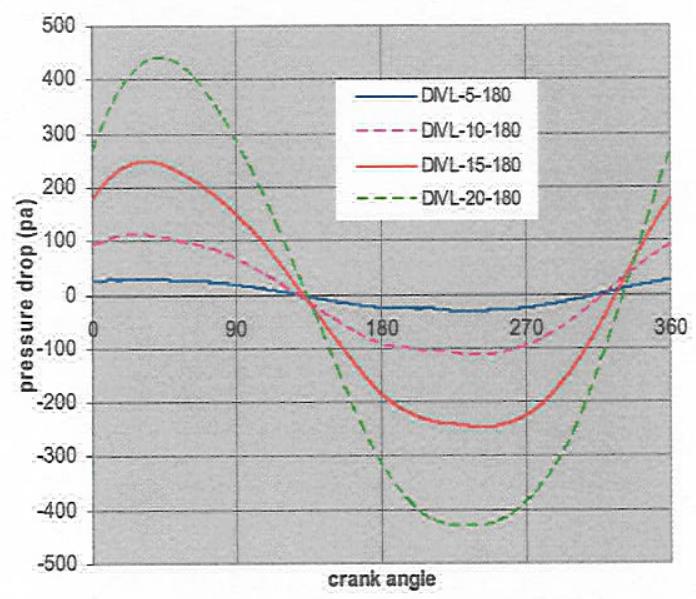

Figure 15. Experimental Pressure Drop Results of Four Long Diverging Inserts (DIVL$5,10,15,20-180$ ) Cases.

For the oscillatory flow condition, the pressure drop from the skin friction is just a small fraction of the total pressure drop in the rectangular duct. For inertial pressure drop, the maximum signals appear at the phase angle of 0 and 180 (at the maximum piston acceleration). For the pressure drop due to local loss, the maximum signals appear at the phase angle of 90 and 270 (at the maximum piston velocity). Since the actual situation is that the pressure drop is due to the total effect of the inertia and the local loss in this series of experiments, the phase angle of the maximum magnitude of the signal is located between 0 and 90 and between 180 and 270 , as shown from Figures 12 to 15 .

A comparison of the pressure drop among different phase angle differences between the two pistons (90 lead, 180 and $90 \mathrm{lag}$ ) is shown in Figure 16 for the abrupt insert and frequency $=20 \mathrm{~Hz}$. At the same frequency, the maximum pressure drop over the cycle for the 90 degree lead or lag, is shown to be less than the maximum pressure drop for the case of the two pistons moving at 180 degree phase difference (for which the working gas experience the maximum velocity and acceleration of all phase differences). 


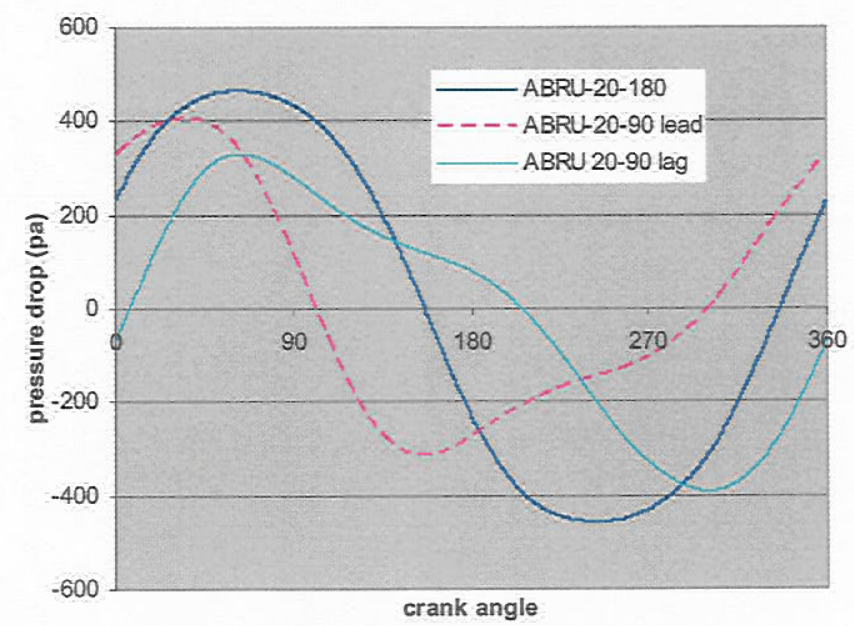

Figure 16. Pressure Drops of Different Phase Difference between the Two Pistons with Abrupt Insert.

\section{Dimensionless Cycle-Averaged Pressure Drop}

To get a relationship between the dimensionless cycle-averaged pressure drops and the kinetic Reynolds number, the cycle-averaged pressure drop was calculated using the following equation (It should be noted that this pressure drop was taken at 1024 equally space crank angle position over the cycle):

$$
\Delta \bar{P}=\sum_{n=1}^{1024}|\Delta P|
$$

The dimensionless mean pressure drop factor and the kinetic Reynolds number are defined as follows:

$$
\begin{aligned}
\Delta P^{*} & =\frac{\Delta \bar{P} D_{h}}{\rho L U_{\max }^{2} / 2} \\
\operatorname{Re}_{\omega} & =\frac{2 \pi \omega D_{h}^{2}}{v}
\end{aligned}
$$

where $\omega$ is the frequency of the piston: $5,10,15$ and $20 \mathrm{~Hz}$. $\mathrm{L}$ is the distance between the two points of pressure drop measurement.

And,

$$
\begin{gathered}
D_{h}=\frac{4 w b}{2(w+b)} \\
U_{\text {max }}=\frac{2 \pi w x_{\max }}{2} \\
x_{\max }=\frac{V_{p i s}}{A_{m}} \\
V_{p i s}=\pi r^{2} \cdot s \\
A_{m}=(w-h) \cdot b
\end{gathered}
$$

where $r$ is the radius of the piston, $s$ is the stroke of the piston. $W$ and $b$ are the width and the height of the rectangular duct respectively. The thickness of the insert is denoted as $h$. The relationship between the dimensionless cycle-averaged pressure drops, with inserts and the kinetic Reynolds numbers are shown in Figure 17. This figure shows the dimensionless pressure drop decreases with increasing kinetic Reynolds number for the cases of oscillatory flow passing through rectangular duct with inserts. At first this may seem a bit surprising. However a look at the definition of dimensionless pressure drop in equation (11), indicates that the pressure drop is divided by the square of piston velocity and piston velocity is proportional to the frequency. 


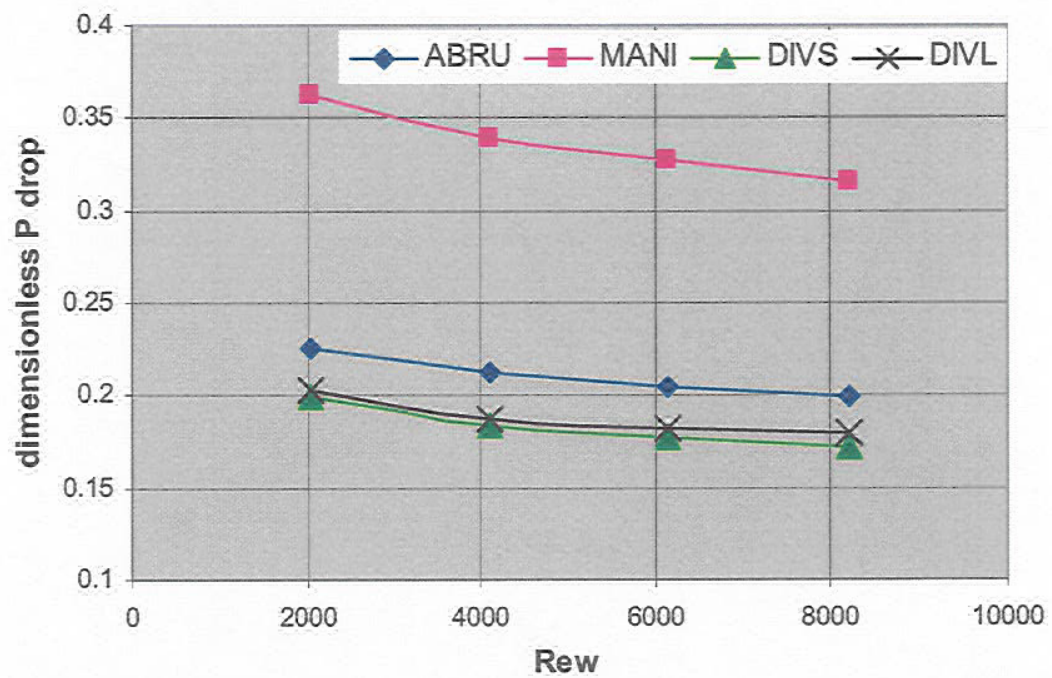

Figure 17. Relationships Between the Cycle-Averaged Dimensionless Pressure Drop and Kinetic Reynolds Number.

\section{E. Comparison of local pressure drop between oscillatory and steady flows}

In order to compare the oscillatory-flow local pressure drop with local pressure drop for the steady flow condition, the inertial pressure drop needs to be estimated so that the local pressure drops can be segregated from the total pressure drop.

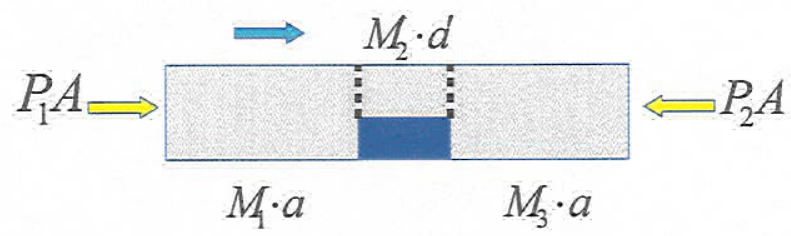

Figure 18. Relationships Between the Pressure Drop and the Acceleration with Insert.

For the test section with the abrupt insert, as shown in Figure 18, the pressure drop from the inertia can be calculated by:

$$
\left(P_{1}-P_{2}\right) A=M_{1} a+M_{3} a+M_{2}^{\prime} a^{\prime}
$$

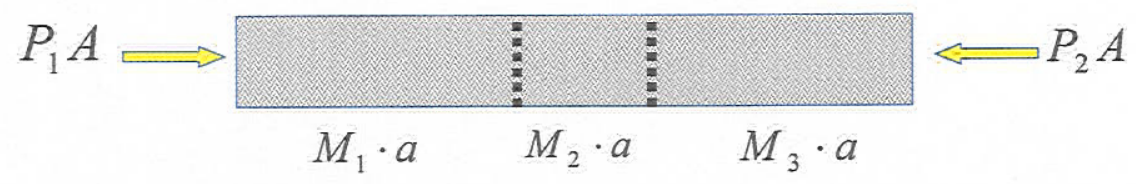

Figure 19. Relationships Between the Pressure Drop and the Acceleration without Insert

For the test section with no insert, as shown in Figure 19, the pressure drop from the inertia is:

$$
\left(P_{1}-P_{2}\right) A=M_{1} a+M_{3} a+M_{2} a
$$


Since the mean pressure for the above two cases are equal, if $M_{2}^{\prime}$ is $1 / \mathrm{n}$ time of $M_{2}, a^{\prime}$ will be n time of a, that is:

$$
M_{2}^{\prime} a^{\prime}=M_{2} a
$$

The same also applies to the other kinds of inserts. Therefore, inertial pressure depends only on the gas acceleration (and therefore the frequency of the pistons) and the mass of the gas being accelerated.

Figures 12 to 15 show the experimental pressure drop signals for different inserts at different frequencies, with the two pistons moving at 180 phase angle difference. Since the pressure drop from the inertia only depends on the frequency, the inertial pressure drop for the case of the abrupt insert is approximately the same as the pressure drop for the no insert case. Thus, by subtracting the no insert pressure drop from the total pressure drop of the abrupt insert case (at the same frequency), the pressure drop left is the local pressure drop due to the expansion and contraction inside the test section, as shown in Figures 20 to 23 .

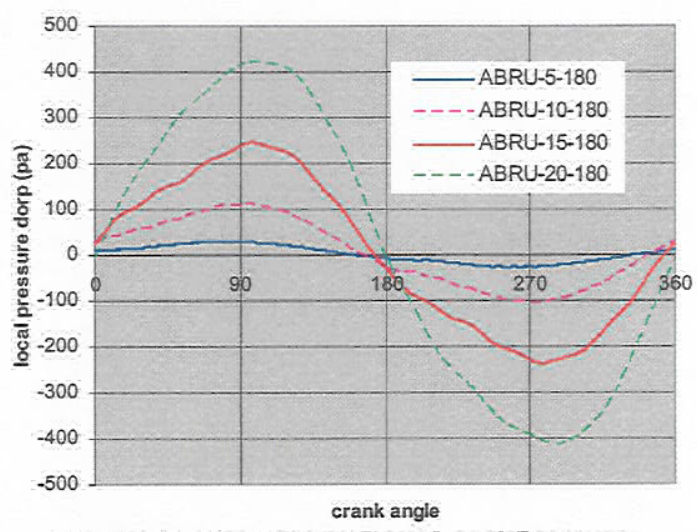

Figure 20. Oscillatory Flow Local Pressure Losses of Abrupt Insert (ABRU-5, 10, 15, 20-180 Cases).

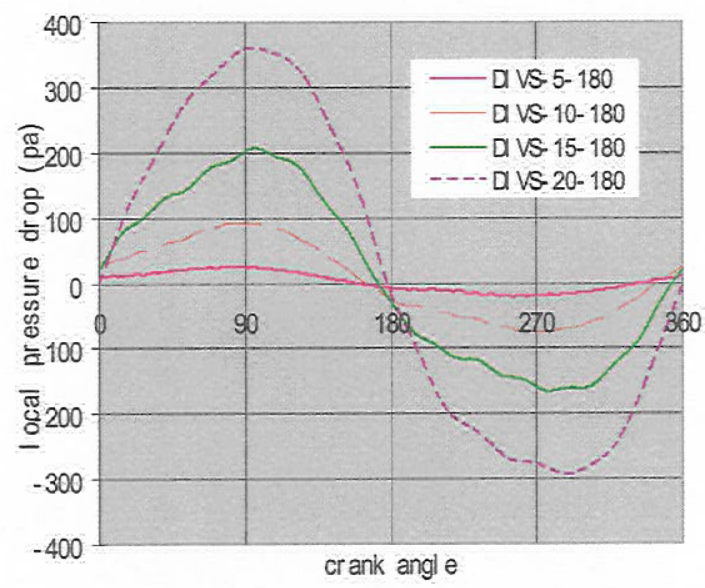

Figure 22. Oscillatory Flow Local Pressure Losses of the Short Diverging Insert (DIVS-5, 10, 15, 20-180 Cases).

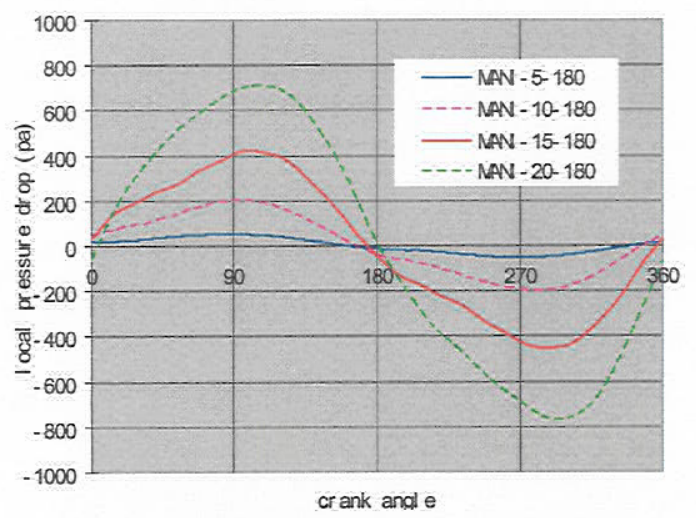

Figure 21. Oscillatory Flow Local Pressure Losses of Manifold Insert (MANI-5, 10, $15,20-180$ Cases).

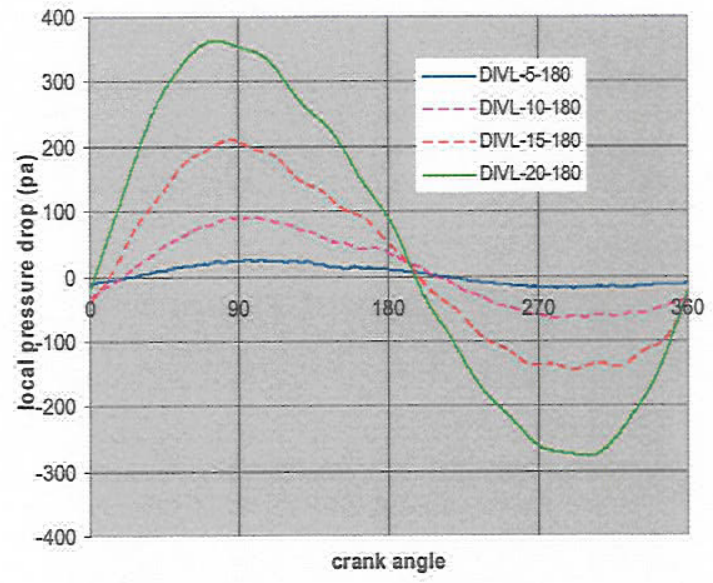

Figure 23. Oscillatory Flow Local Pressure Losses of the Long Diverging Insert (DIVL-5, 10, 15, 20-180 Cases). 
Under the steady flow condition, with the abrupt insert, the local resistance coefficient can be calculated for different geometries of expansion and contraction using equations 5 and 6 , where $D_{1}, D_{2}$ and $\mathrm{u}$ are shown in Figure 24. $\mathrm{D}_{1}, \mathrm{D}_{2}$ are hydraulic diameters of the small section and large section respectively and $u$ is the flow velocity in the small section.

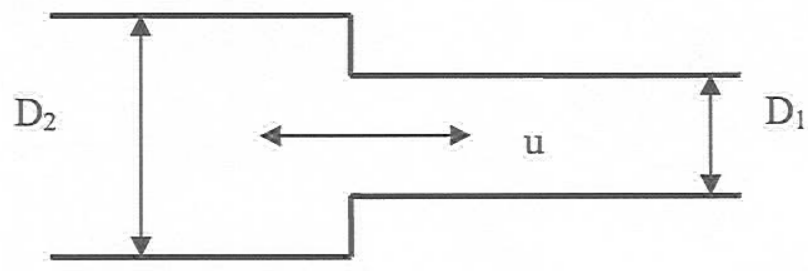

Figure 24. Schematic Diagram of Flow with an Abrupt Change of the Cross-sectional Area.

To calculate the steady-flow pressure drop in the rectangular duct with manifold insert, the total local resistance coefficient was calculated by:

$$
\xi_{\text {tot }}=2\left(\xi_{\text {loc }, e}+\xi_{\text {loc, }, c}\right)
$$

For the diverging insert cases, the steady flow local resistance coefficient should be calculated based on the smooth transition of the section area, as shown in Figure 25. An analytical formula to calculate the steady-flow local resistance pressure drop is only available for the geometry shown in Figure 26. These two conditions are similar because the ratios of the contraction or expansion of the cross-sectional area are the same for the same $\theta$ in these two figures. Therefore, it is reasonable to use the geometry in Figure 26 to approximate the geometry in Figure 25.
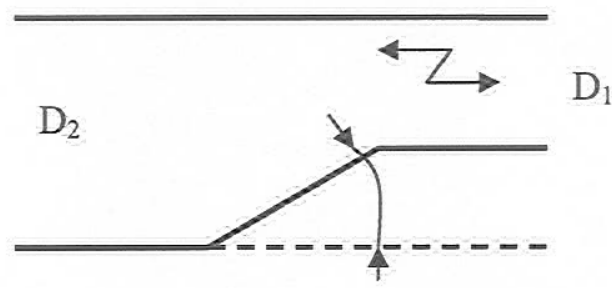

$\theta$

Figure 25. Schematic Diagram of Flow with a Smooth Change of the Cross-section Area.

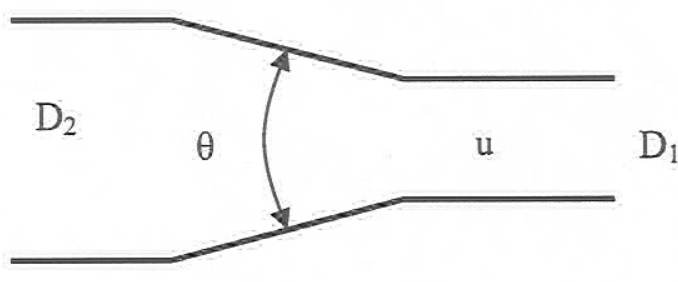

Figure 26. Schematic Diagram of Flow with a Symmetric Smooth Change of the Crosssection Area.

For the geometry shown in the Figure 26, under expansion condition:

$$
\xi_{s, e}=\xi_{r}\left(1-\frac{D_{1}}{D_{2}}\right)^{2}
$$

where

$$
\xi_{r}=0.011 \theta^{1.22}, 7.5^{0} \leq \theta \leq 35^{0}
$$

and $\theta$ is in degrees.

Under the contraction condition, the resistance coefficient is:

$$
\xi_{s, c}=\left(-0.0125\left(\frac{D_{1}}{D_{2}}\right)^{4}+0.0224\left(\frac{D_{1}}{D_{2}}\right)^{3}-0.00723\left(\frac{D_{1}}{D_{2}}\right)^{2}+0.00444 \frac{D_{1}}{D_{2}}-0.00745\right) \times\left(\psi_{r}^{3}-2 \pi \psi_{r}^{2}-10 \psi_{r}\right)
$$

where

$$
\psi_{r}=0.01745 \theta(\theta \text { in degrees })
$$

Therefore, for the steady flow passing through diverging insert, the total local resistance coefficient is:

$$
\xi_{\text {tot }}=\frac{\xi_{t o t, 1}+\xi_{t o t, 2}}{2}
$$

where 


$$
\begin{aligned}
& \xi_{\text {tot }, 1}=\xi_{l o c, c}+\xi_{s, e} \\
& \xi_{t o t, 2}=\xi_{s, c}+\xi_{l o c, e}
\end{aligned}
$$

Figure 27 shows the calculated pressure drop for the steady flow and the cycle-averaged local pressure losses from the experiments for different inserts. It should be noted that we used the cycle-averaged Reynolds number in this case. Typically the maximum Reynolds would be used (in channel flows and as shown earlier in the no-insert cases). However due to the higher harmonics present in the complex geometries (i.e. with inserts, see Figure 16) we decided to use the cycle-averaged Reynolds number. The local (minor) pressure drops of steady flow are almost the same as the cycle-averaged oscillatory pressure drop for the same flow velocity in the rectangular duct with an abrupt insert. The manifold insert cases show the greatest difference between the calculation and the experimental result. It is believed that is because the distance between the two parts of the manifold insert is not far enough to avoid interference between the two parts. The magnitude of the local pressure drops for the diverging short and diverging long inserts are very similar. This indicates that the ratio of the expansion (contraction) is the most important issue in determining the local pressure drops for the smooth transitions of cross-sectional area. In both cases, the experimental results are $1.2 \sim 1.3$ times the calculation results for the steady flow.

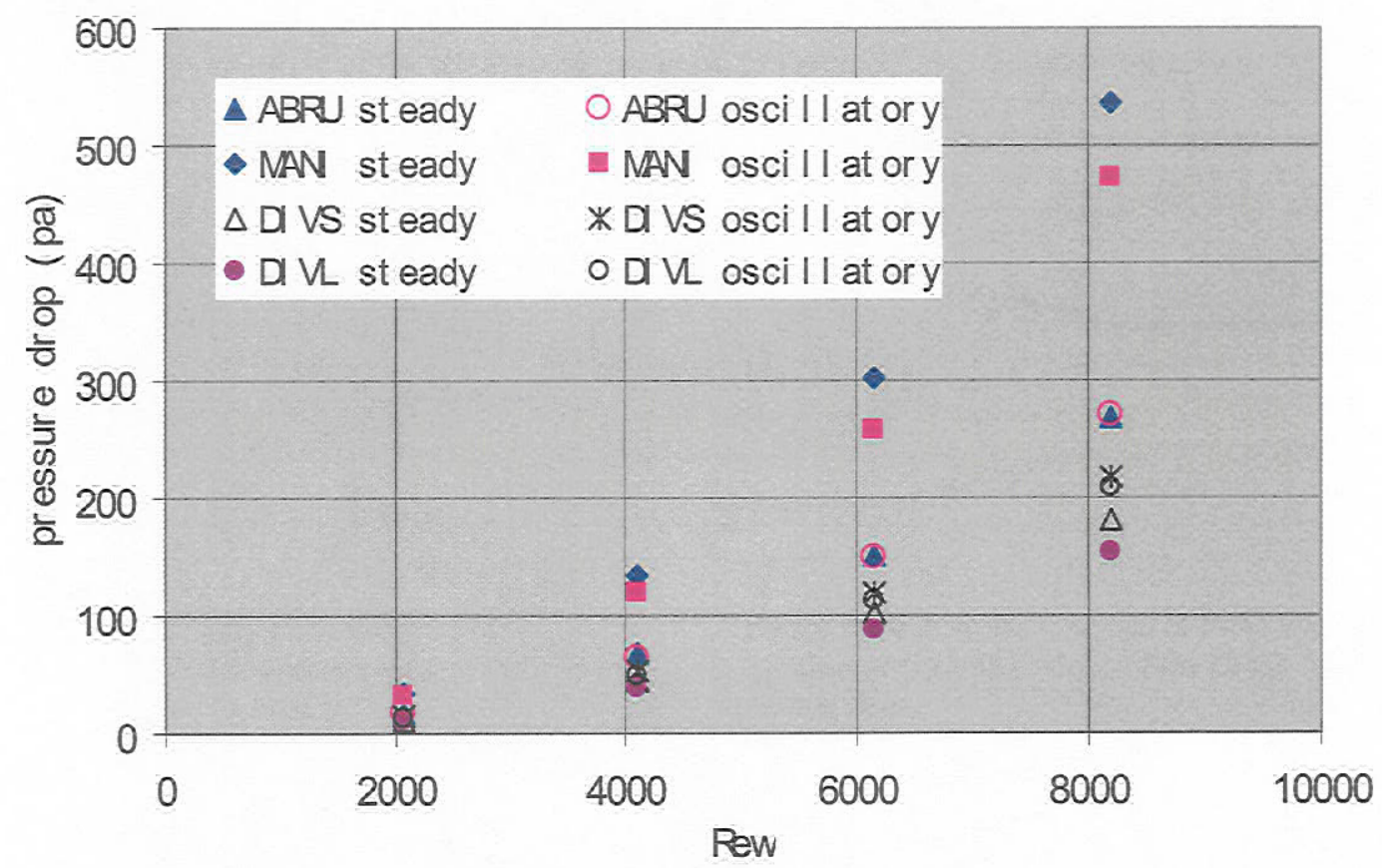

Figure 27. Comparison of Local Pressure Drop Between Experiments (Oscillatory Flow) and Calculation (Steady Flow) for Different Inserts, for the same Cycle-Averaged Reynolds Number.

\section{CONCLUSIONS}

The maximum pressure drop and the cycle-averaged pressure drop of oscillatory flow increase with increasing piston frequency (and accordingly maximum Reynolds number or kinetic Reynolds number). The pressure drop for the oscillating flow in a no-insert rectangular duct is mainly caused by inertia. The oscillating-flow pressure drop in a duct with an insert is due to the total effect of the local (or end effect) pressure drop and the inertia. For the same frequency and geometry, the case of the two pistons moving at the same phase (180 degree) has the highest cycle-averaged pressure drop. The dimensionless pressure drops decrease with the increasing kinetic Reynolds number, which seems reasonable when it is noted that the denominator of the dimensionless pressure drop is proportional to the square of the frequency. For oscillatory flow through a rectangular duct with the inserts considered in this study (abrupt, manifold, 
diverging), the cycle-averaged local pressure drop under the oscillatory-flow condition is almost the same as that under the steady flow condition, for the same geometry.

\section{Acknowledgements}

We are grateful for sponsorship of this contract by the Glenn Research Center of NASA under grant \#NAG3-2482. The contract monitor is Dr. Roy Tew.

Periodicals

\section{REFERENCES}

${ }^{1}$ Makoto TANAKA, Iwao YAMASHITA and Fumitake CHISAKA, "Flow and Heat Transfer Characteristics of the Stirling Engine Regenerator in an Oscillating Flow", JSME International Journal, Series II, Vol.33, No.2, 1990

${ }^{2}$ T.S. Zhao and P. Cheng, "Oscillatory Pressure Drops through a Woven-Screen Packed Column Subjected to a Cyclic Flow", Cryogenics 1996 Volume 36, Number 5

${ }^{3}$ Geon Tae Lee, Byung Ha Kang and Jae-Heon Lee, "Effectiveness Enhancement of a Thermal Regenerator in an Oscillating Flow". Applied Thermal Engineering Vol.18, No.8, pp. 653-660, 1998

${ }^{4}$ Yonglin Ju, Yan Jiang and Yuan Zhou, "Experimental study of the oscillating flow characteristics for a regenerator in a pulse tube cryocooler", Cryogenics 1998, Volume 38, Number 6

${ }^{5}$ Chin-Chia Su and Ray-Hong Lin, "Experimental Studies on Flow in Convergent and Divergent Ducts of Rectangular Cross Section", J. energy res., vol.21, 77-86 (1997)

${ }^{6} \mathrm{X}$. NI and P. Gough, "On the discussion of the dimensionless groups governing oscillatory flow in a baffled tube", Chemical Engineering Science, Vol.52, No.18, pp. 3209-3212, 1997

${ }^{7}$ Barton L. Smith and G. W. Swift, "Power dissipation and time-averaged pressure in oscillating flow through a sudden area change", 2003 Acoustical Society of America [DOI: 10.1121/1.1564022]

${ }^{8}$ Norbert C. J. Chen and Fred P. Griffin, "Effects of Pressure-Drop Correlations on Stirling Engine Predicted Performance", 18th IECEC, 708-713

${ }^{9}$ Taylor, D. R. and Aghili, H. (1984), "An Investigation of Oscillating Flow in Tubes." 19th Intersociety Energy Conversion Engineering Conference. Proceedings (IECEC Paper 849176), pp. 2033-2036.

${ }^{10}$ B. L. Smith and G. W. Swift, "Measuring second-order time-average pressure", 2001 Acoustical Society of America [DOI: $10.1121 / 1.1382615]$

${ }^{11}$ Simsoo Park and Dong-Ryul Lee, "Investigations of Heat Transfer and Pressure Drop Between Parallel Channels with Pseudoplastic and Dilatant Fluids", Journal of Applied Polymer Science, Vol. 89, 3601-3608 (2003)

Books

${ }^{12}$ J.K. Vennard, "One-dimensional flow", in Handbook of Fluid Dynamics, edited by V.L. Streeter (McGraw-Hill, New York, 1961)

${ }^{13}$ Erwin Fried and I. E. Idelchik, "Flow Resistance: A Design Guide for Engineers"

${ }^{14}$ R. K. Shah and A. L. London, "Laminar flow forced convection in ducts: a source book for compact heat exchanger analytical data", Advances in heat transfer. Supplement 1

Reports, Theses, and Individual Papers

${ }^{15}$ Hoehn, , F. W., "Stirling Laboratory Research Engine: Preprototype Configuration Report", JPL Publication 82 13, NASA, February 1982

${ }^{16}$ Wei Du, "Development of an Oscillating Flow and Heat Transfer Experimental Facility", M.S. Thesis, Cleveland State University, 1993 